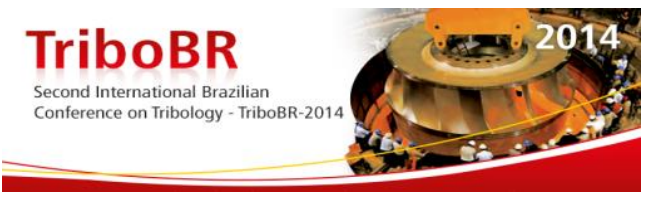

\title{
GENESIS AND STABILITY OF TRIBOLAYERS IN SOLID LUBRICATION: CASE OF PAIR DLC-STAINLESS STEEL*
}

\author{
Diego Berti Salvaro ${ }^{1}$ \\ Márcio Silvério ${ }^{2}$ \\ Cristiano Binder ${ }^{3}$ \\ Roberto Binder ${ }^{4}$ \\ Renan Schoreder ${ }^{5}$ \\ Deise Rebelo Consoni ${ }^{6}$ \\ Aloisio Nelmo Klein ${ }^{7}$ \\ José Daniel Biasoli de Mello ${ }^{8}$
}

\begin{abstract}
The morphology, dimensions and chemical composition of tribolayers strongly depend on the pressures and temperatures acting on the contact. They are formed by reactions between the surfaces in contact with each other as well as with the atmosphere, lubricants and possible contaminants. In this paper the influence of test time $(180,500,1000$ and $2500 \mathrm{~h})$ into the formation and characteristics of tribolayers in pairs DLC-stainless steel tested under refrigerant gas R134a atmosphere without presence of lubricating oil was analyzed. The characterization was performed using scanning electron microscopy, energy dispersive spectroscopy (SEM-EDS) (morphology and chemical composition) and white light interferometry (dimensions). The tribolayers thicknesses ranged from 100 to $500 \mathrm{~nm}$ and they were composed by elements originated from mutual transfers between the tribological pairs as well as oxides, being more pronounced on the stainless steel surface. The results show that the tribolayers are chemically stable (maintained the same composition over time) and the thickness remained stable after a thousand hours of testing.
\end{abstract}

Keywords: Tribology; Tribolayer; Diamond-like carbon (DLC).

1 Physicist, Master student, Materials Laboratory, Universidade Federal de Santa Catarina, Florianópolis, Santa Catarina, Brasil.

2 MSc, Research, Tribology Laboratory, Embraco, Joinville, Santa Catarina, Brasil.

3 Dr. Ing., Research, Materials Laboratory, Universidade Federal de Santa Catarina, Florianópolis, Santa Catarina, Brasil.

4 MSc, Research, R\&D solutions, Embraco, Joinville, Santa Catarina, Brasil.

5 MSc, Research, R\&D solutions, Embraco, Joinville, Santa Catarina, Brasil.

6 Dr. Ing., Research, Central Laboratory of Electron Microscopy, Universidade Federal de Santa Catarina, Florianópolis, Santa Catarina, Brasil

7 Doc. Ing., Professor, Materials Laboratory, Universidade Federal de Santa Catarina, Florianópolis, Santa Catarina, Brasil.

8 Doc. Ing., Professor, Materials Laboratory, Universidade Federal de Santa Catarina, Florianópolis, Santa Catarina, Brasil.

\footnotetext{
* Technical contribution to the $2^{\text {nd }}$ International Brazilian Conference on Tribology - TriboBR 2014, November $3^{\text {rd }}$ to $5^{\text {th }}$, 2014, Foz do Iguaçu, PR, Brazil.
} 


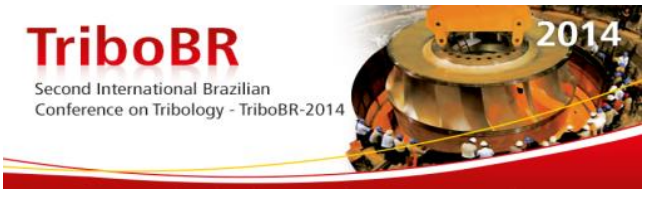

\section{INTRODUCTION}

Considerable fraction of the energy generated in the world is lost due to friction and wear in mechanical systems. According to Jost [1] it is possible to reduce these losses by up to $20 \%$ only applying existing knowledge and techniques.

Fluid lubrication is widely applied in order to reduce friction and wear, however, environmental factors suggest the industry to reduce or even eliminate the lubricating oils. In addition, there are applications where the oil presence is not possible, for example, environments under high temperature and pressure which can promote chemical degradation of the oil. Contaminant-free systems such as those used for food and pharmaceutics equipment are also instances where dry lubrication is potentially interesting [2]. Therefore, improving the tribological performance of mechanical elements is a prerequisite for new products development and manufacturing processes [3].

Oil less tribo systems represent a new challenges for the science and surface engineering, stimulating new projects on coatings and self-lubricant material. Amorphous carbon coatings, known as diamond-like carbon (DLC) have been an alternative in many technological applications, such as hard coating for tools, automotive parts, computer hard drives and micro electro mechanical systems (MEMS). The applications are mainly associated with its high hardness, high chemical inertness and solid lubrication capacity [4]. The DLC family consist of amorphous carbon hydrogenated alloys $(\mathrm{a}-\mathrm{C}: \mathrm{H})$, as shown in the ternary diagram on figure 1, where different families of DLC are characterized by the percentage of hybridizations $\mathrm{sp}^{2}, \mathrm{sp}^{3}$ and amount of hydrogen [5]. In addition, doping elements are incorporated into DLC to modify its properties, such as silicon (a-C:H:Si) which decreases the free energy and the residual stress of the coating modifying its tribological behavior [6]. Other common dopant elements in DLC are tungsten, titanium, molybdenum and chromium.

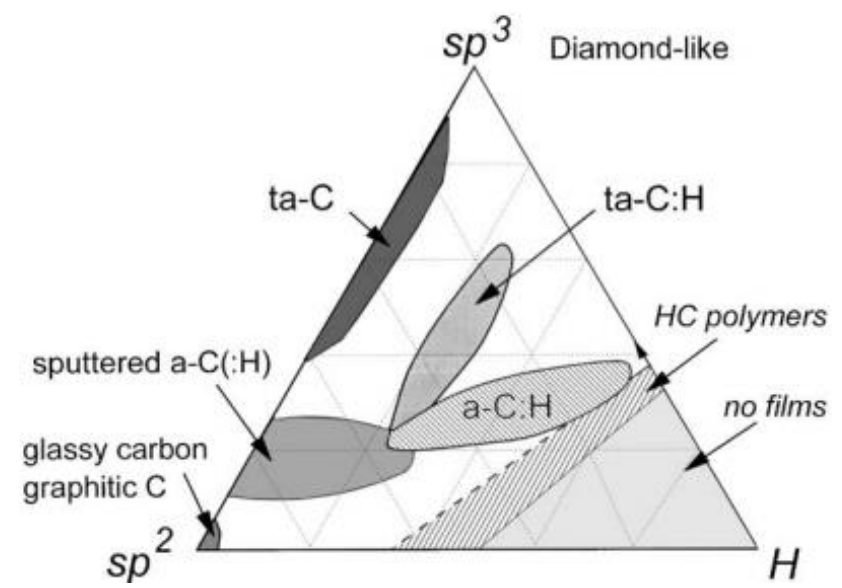

Figure 1: Ternary phase diagram for hydrogenated amorphous carbon alloys [3].

The low coefficient of friction associated with DLC is often associated with tribolayer formation, which is a result mainly of transfer material from DLC to the counter body and vice versa [6-8]. The genesis of these tribo layers is strongly dependent on environment. For atmospheres such as air, oxygen or nitrogen, the increase of humidity usually reduces coefficient friction of DLC-steel contact $[9,10]$. In a study performed by de Mello, Binder et al. [11], it was shown that the presence of protective atmosphere (R600a) modifies the chemical structure of tribolayer generated on the counter body, reducing the friction coefficient and the wear rate of

* Technical contribution to the $2^{\text {nd }}$ International Brazilian Conference on Tribology - TriboBR 2014, November $3^{\text {rd }}$ to $5^{\text {th }}$, 2014, Foz do Iguaçu, PR, Brazil. 


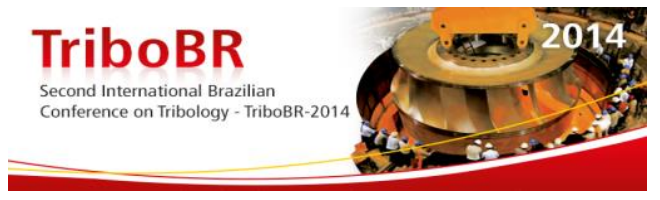

the system (DLC / steel AISI 52100). In another work performed by Demas and Polycarpou [12] pin-on-disc tests were performed with gray cast iron (pin and disc) without lubrication and different atmospheres $\left(\mathrm{O}_{2}, \mathrm{CO}_{2}, \mathrm{~N}_{2}, \operatorname{Ar}\right.$ and $\left.\mathrm{R} 134 \mathrm{a}\right)$. Under $\mathrm{O}_{2}$ atmosphere, the wear is ruled by the oxidation that occurs on the wear track, whereas in air and R134a it also contains an adhesive component. Under $\mathrm{N}_{2}$ atmosphere, the wear is dominated by adhesion, while in $\mathrm{CO}_{2}$ there is a slight polishing on the surface, removing only superficial asperities, thus leading to the best tribological performance among the tested atmospheres.

The tribo layers settle on the real contact area, therefore, rule the tribological behavior of tribo systems. Their dimensions are reduced (nanometers), and this factor hinders to understand their formation and stabilization. Tribo layers are formed from physicochemical interactions between the surfaces in contact and relative motion, which ranges from mutual transfer of materials and reactions between atmosphere, lubricants and contaminants present in the contact [13].

The contact conditions affect the formation and destruction of tribo layers, i.e., the stability of tribo layers depends on contact evolution. When the formation and destruction rates of tribo layers acquire the same values, the tribo layers achieve a certain mechanical stability, which from the point of view of tribological performance is fundamental to stability contact.

This study aims to understand the genesis of tribo layers formed in DLC-stainless steel pair with reciprocating movement and controlled atmosphere, as well as to evaluate their mechanical and chemical stability.

\section{MATERIALS AND METHODS}

The tested tribological pairs was formed by a piston and cylinder coaxially coupled, where the cylinder is made of stainless steel 304 and the piston of AISI 52100 steel coated with chromium nitride $(\mathrm{CrN})$ (thickness of 1.5-2.0 $\mu \mathrm{m}$ ) and DLC (thickness $1.0 \mu \mathrm{m})$. The experiments imposed a reciprocating movement $(1.7 \mathrm{~mm}$ amplitude and frequency of $350 \mathrm{~Hz}$ ) in a tetrafluoroethane (R134a) gas atmosphere.

Nine experiments were conducted, being three of them with 180 hours duration and two more for each period of 500, 1000 and 2500 hours.

After tests, the stainless steel cylinders were sectioned in order to access the contact areas. The body and counter body surfaces were cleaned with cotton and absolute ethyl alcohol. At a first glance, darker regions were observed (highlighted in figure 2) where, in principle, it would be easier to find tribo layers.

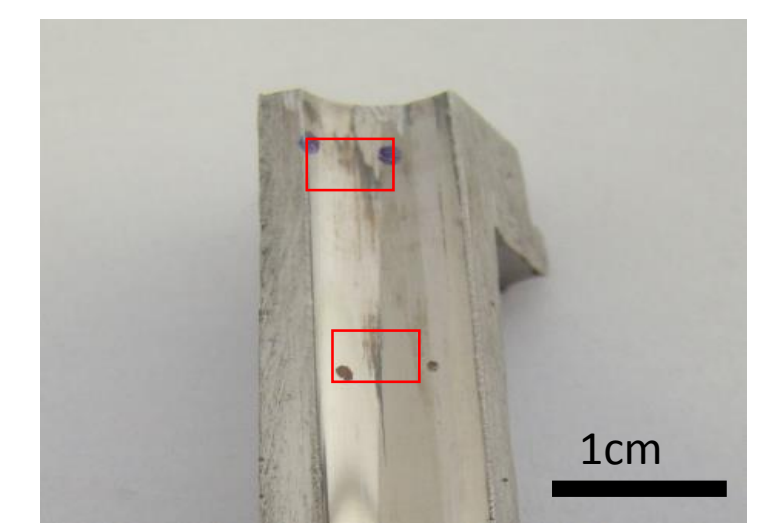

Figure 2: Possible tribo layers highlighted in red.

\footnotetext{
* Technical contribution to the $2^{\text {nd }}$ International Brazilian Conference on Tribology - TriboBR 2014, November $3^{\text {rd }}$ to $5^{\text {th }}$, 2014, Foz do Iguaçu, PR, Brazil.
} 


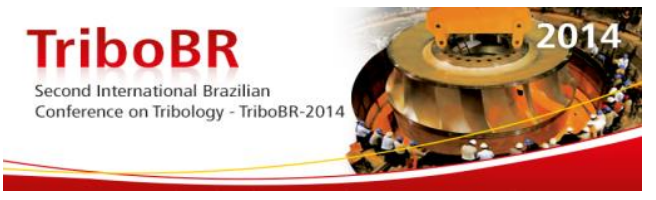

The relevant regions were analyzed by using Scanning Electron microscopy (SEMJEOL JSM-6390LV).

For data acquisition of dimensional analysis, the white light interferometer (Zygo New View 7300) was used. MoutainsMap ${ }^{\circledR}$ software was used to perform the measurement of the average tribo layers thicknesses. The procedure consists in selecting two regions, one within the tribolayer and another on the original surface, and then the average height difference between these two regions can be calculated. On figure 3 there are two examples of thickness measurement of tribo layers for two different periods tests (500 and 2500 hours). Regions labeled 1 refer to the original surface and label 2 refer to the tribolayer. The measurements were repeated five times at different points.

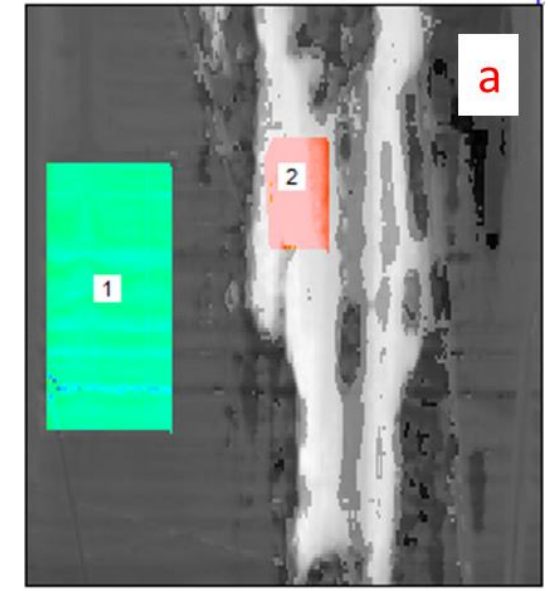

Height difference :

$0.619 \mu \mathrm{m}$

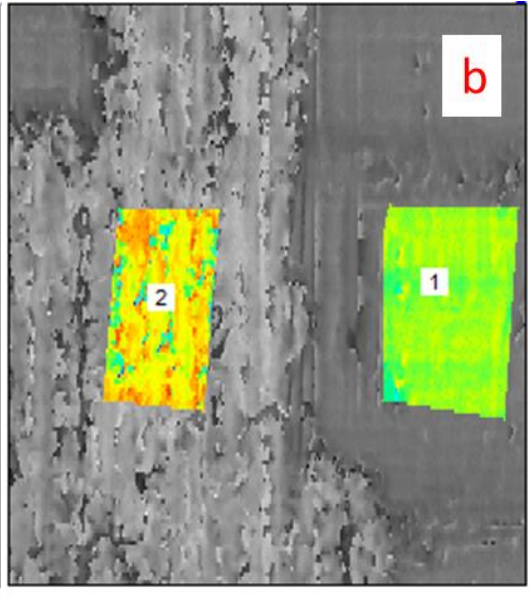

Height difference : $\quad 0.44 \mu \mathrm{m}$

Figure 3: Examples of tribo layers thickness measurement on the stainless steel surface. (a) 500 hours (b) 2500 hours.

\section{RESULTS AND DISCUSSION}

\subsection{SEM and EDS}

Figures 4 and 5 show typical tribolayers present in DLC and stainless steel surfaces, respectively. In the right columns, the images were obtained by using backscattered electron and evidence variations in average atomic number.

Although tribolayers are found in both body and counterbody, they were more pronounced on the stainless steel surfaces.

* Technical contribution to the $2^{\text {nd }}$ International Brazilian Conference on Tribology - TriboBR 2014, November $3^{\text {rd }}$ to $5^{\text {th }}$, 2014, Foz do Iguaçu, PR, Brazil. 

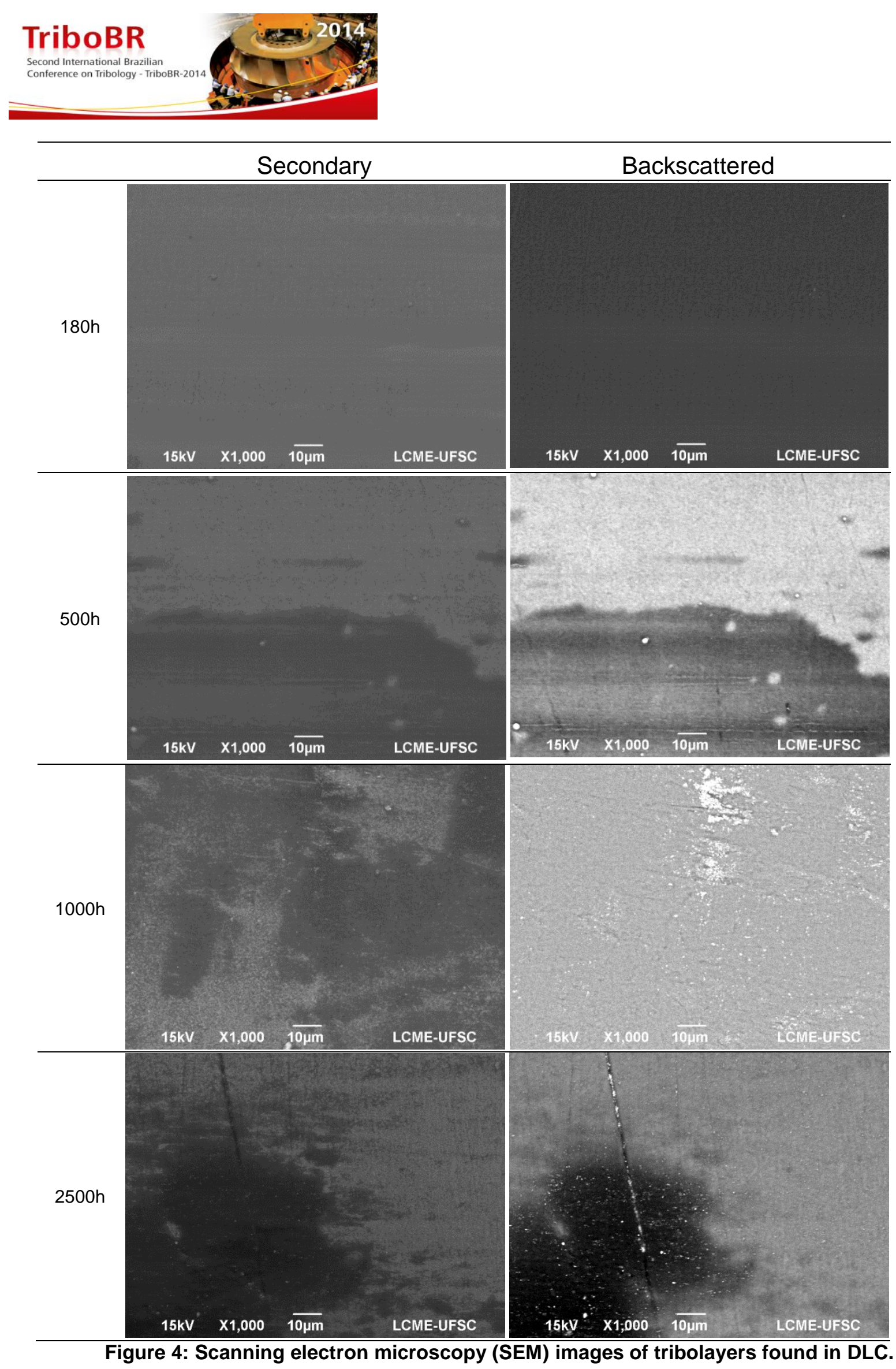

* Technical contribution to the $2^{\text {nd }}$ International Brazilian Conference on Tribology - TriboBR 2014, November $3^{\text {rd }}$ to $5^{\text {th }}$, 2014, Foz do Iguaçu, PR, Brazil. 


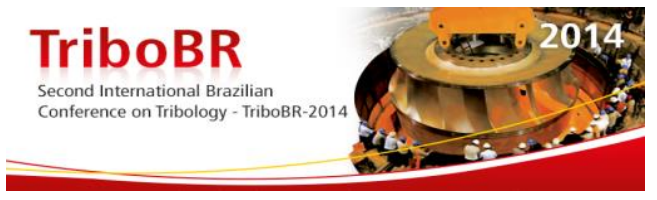

important, figure 7, and its origin may be associated to material transfer from DLC coating. It is also noticeable the high oxygen of the tribolayer clearly indicating an oxidation process in accordance with $\mathrm{Wu}$, Pai and Hon results [14].

Due to electron beam penetration, the substrate has a direct influence on EDS results. Thereby, reduction of the chromium concentration on the rubbed regions of DLC occurred due to coating thinning, which allowed more interaction between the electron beam and the substrate atoms (AISI 52100) below the CrN layer. The chromium concentration on tribolayers associated with the stainless steel decreased when compared to the original surface (Figure 7).
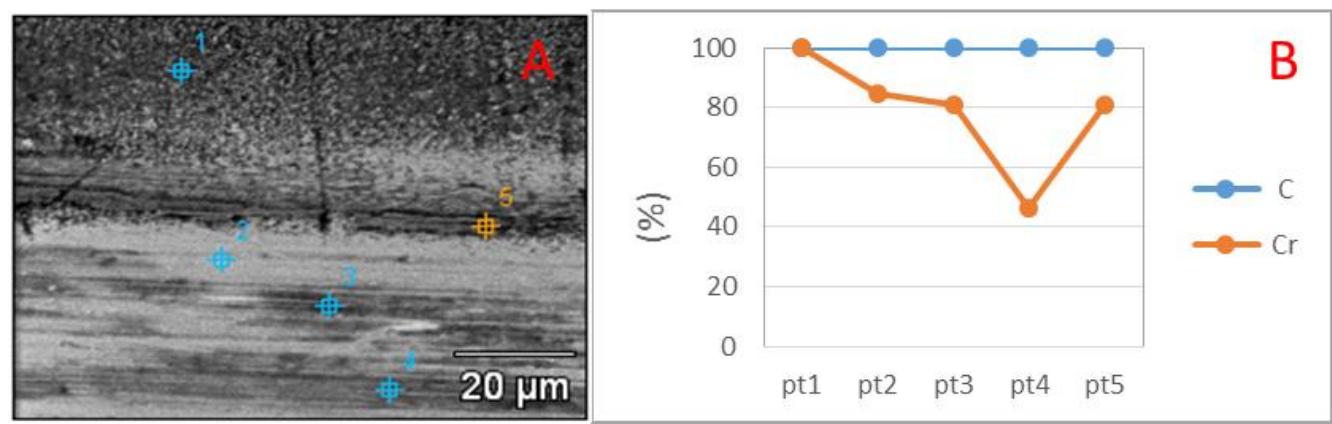

Figure 6: Variation of the carbon and chromium concentration outside (1) and inside $(2,3,4,5)$ of tribolayer over DLC. (A) Measurements location. (B) Evolution of $\mathrm{C}$ and $\mathrm{Cr}$ concentration.
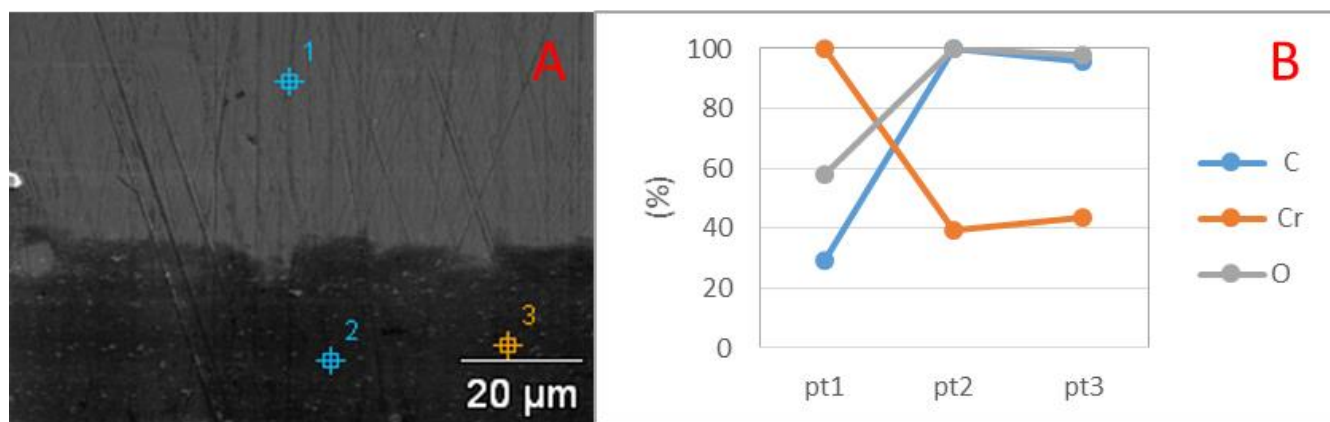

Figure 7: Variation of the carbon, chromium and oxygen concentration outside (1) and inside $(2,3)$ of tribolayer over stainless steel. (A) Measurements location. (B) Evolution of $\mathrm{C}, \mathrm{Cr}$ and $\mathrm{O}$ concentration.

Figure 8 shows the evolution of carbon, chromium and oxygen concentrations with test time for tribolayers related to stainless steel surfaces. The atomic percentage of oxygen slightly decreased for test times up to 1000 hours and after that the values remain almost constant. The same behavior is observed for chromium, however, the initial drop is more abrupt and occurs between 180 and 500 hours. In spite of the large dispersion presented by the carbon amount, it is possible to observe a reverse trend in relation to chromium evolution, indicating the formation of carbon-rich tribolayers originated from the DLC coating. The figure 9 shows the evolution of carbon end chromium concentrations with test time for tribolayers related to DLC surfaces. The same inverse behavior between the carbon and chromium concentration was observed again, indicating a possible mutual transfer of material between the surfaces [15].

In synthesis, tribo-reactions given rise to tribolayers are active up to a thousand hours of testing time. After that time, the tribolayers remain chemically quite stable.

\footnotetext{
* Technical contribution to the $2^{\text {nd }}$ International Brazilian Conference on Tribology - TriboBR 2014, November $3^{\text {rd }}$ to $5^{\text {th }}$, 2014, Foz do Iguaçu, PR, Brazil.
} 


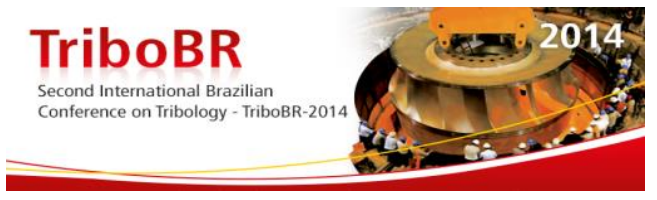

The concentration of chromium, carbon and oxygen presented a significant variation between 180 and 1000 hours. After that time, the tribolayers remain chemically quite stable. In addition, the thickness of tribolayers also varied in the same interval, so that the thicker the layer on the body, the thinner the layer on the counterbody, suggesting a mutual destruction and formation of tribolayers until a stable state is reached.

\section{Acknowledgments}

The authors would like to thank Empresa Brasileira de Compressores - Embraco (Brazilian Company of Compressors) for financial support and infrastructure for this work. The authors also thanks the Central Laboratory of Electron Microscopy (LCME) of the Federal University of Santa Catarina for carrying out SEM analysis.

\section{REFERENCES}

1 Jost HP. Tribology - Origin and Future. Wear, p. 1-17, 1990.

2 Schroeder R, et al. Internal lubricant as an alternative to coating steels. Metal Powder Report, p. 24-31, 2010.

3 Zhiqiang $\mathrm{F}$, et al. Tribological performance of DLC coatings deposited by ion beam deposition under dry friction and oil lubricated conditions. Vacuum, p. 14-18, 2013.

4 Viana GA, et al. Diamond-like carbon deposited by plasma technique as a function of methane flow rate. Diamond \& Related Materials, p. 756-759, 2010.

5 Robertson J. Diamond-like Amorphous Carbon. Materials Science Engineering, p. 129281, 2002.

6 Donnet C. Recent progress on the tribology of doped diamond-like and carbon alloy coatings: a review. Surface and CoatingsTechnology, p. 180-186, 1998.

7 Ronkainen $\mathrm{H}$, et al. Effect of tribofilm formation on the tribological performance of hydrogenated carbon coatings. Surface and Coatings Technology, p. 87-94, 1996.

8 Grill A. Review of the tribology of diamond-like carbon. Wear, p. 143-153, 1993.

9 Lifang X, Guang L. The frictional behavior of DLC films against bearing steel balls and Si3N4 balls in different humid air and vacuum environments. Wear, p. 1077-1084, 2008.

10 Erdemir A, et al. Characterization of transfer layers on steel surfaces sliding against diamond-like hydrocarbon films in dry nitrogen. Surface and Coatings Technology, p. 559-563, 1995.

11 Mello JDB, et al. Effect of the actual environment present in hermetic compressors on the tribological behaviour of a Si-rich multifunctional DLC coating. Wear, p. 907-915, 2009.

12 Demas NG, Polycarpou AA. Tribological investigation of cast iron air-conditioning compressor surfaces in CO2 refrigerant. Tribology Letters, p. 271-278, 2006.

13 Luo Q, et al. Effect of Tribofilm Formation on the Dry Sliding Friction and Wear Properties of Magnetron Sputtered TiAICrYN Coatings. Tribology Letters, p. 113-124, 2009.

14 Wu WJ, Pai TM, Hon MH. Wear behavior of silicon-containing diamond-like carbon coatings. Diamond and Related Materials, p. 1478-1484, 1998.

15 Suzuki M, Saito T, Tanaka A. Tribological properties of DLC films against different steels. Wear, p. 83-87, 2013.

16 Olofsson J, et al. On the influence from micro topography of PVD coatings on friction behaviour, material transfer and tribofilm formation. Wear, p. 2046-2057, 2011.

\footnotetext{
* Technical contribution to the $2^{\text {nd }}$ International Brazilian Conference on Tribology - TriboBR 2014, November $3^{\text {rd }}$ to $5^{\text {th }}$, 2014, Foz do Iguaçu, PR, Brazil.
} 